that enough material for a broad estimate of classical and mediaeval chemistry and alchemy has already reached print. Multhauf does, however, emphasize the work of some people who, in his opinion, have been neglected in the three important stages of the genesis of Greek, Arabic and Latin alchemy, namely, Agathodaimon, Balinus and Ibn Juljul.

Multhauf does not waste space on summaries of wellknown works. For example, his account of Geber concentrates on its style and its relation to other works, so that the reader who wants to know a fair amount of what is in the Summa perfectionis will have to turn back to Stillman and others. But the reader who reads the Summa perfectionis itself will find Multhauf's few pages an excellent stimulus to making his own analysis of its contents.

The same help to understanding of the original works occurs again and again. In the chapter on medical chemistry: "The history of the chemistry of mercury again raises the question of the sense in which we are to suppose that substances were 'known'. By heating mercury in air Geber tells us that he 'coagulates' it, and in the thermal decomposition of the nitrate he 'prepares it most red'. The author of the De alumnibus explains similarly the reaction which led him to corrosive sub. limate. We can be reasonably confident that we know what was made in these processes, but can we say that the substances were known to their "discoverers'." The ideas of a substance or a pure substance or a chemical species were all to evolve very slowly, to reach certainty only long after the period of this book (and to dissolve again into uncertainty in our own time).

The chapter on which the book hinges has a title which is very congenial to those followers of Collingwood who want to recover the personal experience in past events: "The Rise of the Chemist". Chemistry is what chemists do, and Multhauf emphasizes this in his chapter on the practice of chemistry by individuals and groups in the century before the genesis of scientific chemistry as we know it.

The economic view must also be presented, and Multhauf does this under the two main heads of "Metals" and "Heavy Chemicals". It is a pity that he does not carry his discussion of metals further into the eighteenth century but, because there is no obvious stopping place after Cramer or Réaumur, it is hard to suggest how else this chapter could have been written. If I felt tempted to say the same sort of thing about the chapter on heavy chemicals, it would be because I forgot that the author claims only to discuss "origins". The heavy chemical industry of revolutionary France is a fascinating subject, but it rested on a long past, and it is for this kind of event, which is still so little appreciated, that Multhauf sets out to prepare us.

Multhauf refers in his preface to the increasing professionalization of the study of the history of science. This is a professional's book for professionals, but like so many of the best books of which this can be said, it will bring great pleasure to anyone, scientist or not by occupa. tion, who can claim to be scientifically educated.

Frank Greenaway

\section{THEORY OF ADHESION}

Treatise on Adhesion and Adhesives

Edited by Robert L. Patrick. Vol. 1: Theory. Pp. xi+476. (London: Edward Arnold (Publishers), Ltd.; New York: Marcel Dekker, Inc., 1967.) 175s. net.

IN a broad appreciation of its meaning, the story of adhesives and adhesion has its origin deep in the veils of time. It is clear both by inference as well as by example that man was engaged in its practice long before recorded history. For his many purposes we may presume that he was moderately content with what he believed possible and with the success achieved and we may also conclude that his materials and techniques assumed horizons which only slowly extended over many thousands of years. During the present century, however, there has been a dramatic upsurge of interest in the subject, as, of course, there has with many others. The nature of adhesives has now been recognized and consequently many new adhesives have appeared; the role of the interface, the character of material defects and many other aspects are beginning to reveal themselves. This coming of age has drawn on and will continue to draw on a wealth of scientific and technological advances so that what was once often regarded as a black art is now beginning to flourish as a scientific discipline. Indeed, I for one would not be surprised if, in the challenge of this technological age, those academic institutions which offer some specialization within their curricula might very well take it upon themselves to include subjects such as adhesion, combining as they do so many experiences at an advanced level. In this way it could promote a native stimulus, other than the examination system, so desirable for a student preparing himself for the great unknown.

The assembly of hitherto specialized knowledge under one cover has meant an increasing trend towards the edited textbook and the Treatise on Adhesion and Adhesives is no exception. The present volume is the first of three on the subject under the general editorship of Dr R. L. Patrick. The second volume, to be published in 1968, will be concerned with materials, including adhesives themselves with special topics such as fibre, high temperature and glass-resin adhesion, as well as with brazing, welding and so on. The third volume is to be restricted to applications. The first volume, which relates to theory, opens with a general introduction followed by chapters on intermolecular and interatomic forces. by R. J. Grood, adsorption of polymers, by R. R. Stromberg, the mechanisms of adhesion, by J. R. Huntsberger, role of bulk properties of the adhesive, by Turner Alfrey, jun., rheology of polymers used as adhesives, by D. H. Kaelble, fracture mechanics applied to adhesive systems, by G. R. Irwin, variables and interpretation of some destructive cohesion and adhesion tests, by J.L. Gardon, and surface chemistry, by F. M. Fowkes. The author and subject indices are preceded by a list of symbols used in the text.

It would appear that the editor has given his authors a fair amount of licence and yet despite his inference of "angry young men" no suggestion of prejudice or subtle irresponsibility is dominant or even apparent. To a certain extent, as in any textbook, much of the subject matter is available in separate publications and no doubt, because of this, some readers will find some imbalance in the length of chapters. Again, it may cause some surprise that in a book which speaks easily of stress tensors in one chapter. there is a need to define the imaginary unit in another. Others may regard with gloom the dismissal of nondestructive testing. But these are minor criticisms and the editor and authors are to be congratulated on a most interesting and stimulating production, despite some similarity both in title and perhaps less in treatment with another recent publication. The presentation and style are good, diagrams and tables are adequate, and with the exception of one authoritative chapter, references are ample and surprisingly, for a collated textbook, up to date. In view of occasional but slight duplication, I feel that the internal reference system might have been improved but even this works to advantage in promoting a system of self contained chapters. The book will commend itself primarily to physicists, physical chemists and materials scientists as well as new and established researchers in the field of adhesion itself, and although the price, which is perhaps partly a reflexion of the publishers' well placed confidence, will preclude much personal ownership in this country, it will, as it should, find its way onto many bookshelves, and, I hope, into many more laboratories.

R. P. SHELDON 